\title{
Patient willingness to be seen by a physician associate in Ireland
}

\author{
Pauline Joyce*1, Richard Arnett ${ }^{2}$, Arnold Hill ${ }^{1}$, Roderick S. Hooker ${ }^{3}$ \\ ${ }^{1}$ Royal College of Surgeons in Ireland, School of Medicine, Dublin, Ireland \\ ${ }^{2}$ Quality Enhancement Office at Royal College of Surgeons in Ireland, Dublin, Ireland \\ ${ }^{3}$ Health Policy Analyst, Ridgefield, WA, USA
}

Received: April 9, 2018

DOI: $10.5430 /$ ijh.v4n2p41
Accepted: June 7, 2018

URL: https://doi.org/10.5430/ijh.v4n2p41

Online Published: July 10, 2018

\begin{abstract}
Background: The physician associate (PA) role was piloted in Dublin, Ireland between 2015 and 2017. However, the concept of a PA and the acceptance of their role in Ireland had not been explored.

Objective: To investigate the willingness of Irish citizens to be seen by a PA based on medical scenarios in a typical clinical setting.

Design: A mixed methods study was undertaken. A preference survey, with three medical scenarios, gave participants a choice to be treated by a PA or a doctor, with two time trade-off options offered. Responses were supported with qualitative text. Four hundred people were invited to participate as surrogate patients.

Setting and participants: In 2017 a total of 270 respondents took part in the study $(67.5 \%)$ in two hospitals (one private and one public) in Dublin. The mean age was 60 ; male $(n=142)$ and female $(n=128)$ respondents.

Findings: In total, $95 \%$ of the respondents chose to see a PA over a doctor based on the scenarios presented and a wait time of 30 minutes. Wait time, trust, competency and the severity or seriousness of the medical condition were categorized into three themes for choosing the PA over the doctor. The "surrogate patient" decisions made by this sample were influenced by knowing that the PA is supervised and can check decisions with his/her supervizing physician.

Conclusion: These findings are consistent with studies carried out in other countries where willingness to be seen by a PA is neither age nor gender specific. Patient preference seems to concur around the importance of trust and confidence in the medical provider.
\end{abstract}

Key Words: Physician associate, Willingness to be seen, Wait time, Ireland, Physician assistant, Time trade-off

Is é do shláinte do saibhreas.

(Your health is your wealth)

\section{INTRODUCTION}

The Physician Associate (PA) role (also known as physician assistants elsewhere) is recognized by UK policy makers and doctors as an opportunity to expand the medical work- force. However, the acceptance of a PA from the patients' perspective has not been extensively explored in Europe. ${ }^{[1]}$ Economic and behavioural sciences substantiate that patients are willing to make trade-offs in medical care at different

*Correspondence: Pauline Joyce, EdD; Email: pjoyce @rcsi.ie; Address: Royal College of Surgeons in Ireland, School of Medicine, Dublin, Ireland. 
times in their lives, for different objectives, under various circumstances. Access to care may be one of those trade-offs that patients are willing to make if a lesser-trained but equally skilled provider is available. ${ }^{[2-4]}$

The purpose of this study was to determine the extent to which PAs are accepted by citizens in Ireland (see Figure 1) Asking this highly relevant question is at the heart of policy initiatives to deploy PAs across health systems and demographics. To date, PAs have been introduced into various countries without asking for patient input. What is missing in those cases is an understanding of whether these providers are in society's best interest and how patients view them. Understanding patient preferences and willingness to be seen by a clinician who is trained in medical care management, but is not a doctor, is important to guide workforce planning and justify the introduction of new models of healthcare. Studies on patient willingness to be seen by a PA reveals that Americans, Australians, Canadians and Dutch citizens are willing to access new models of care over traditional options, as long as their care needs are met. ${ }^{[2-5]}$ An opportunity to explore the question of the societal benefits of PAs is important prior to people having the experience of being cared for by a PA. This work takes advantage of other exploratory studies which have examined the concept of "willingness to be seen" and with which these findings concur. ${ }^{[2-5]}$

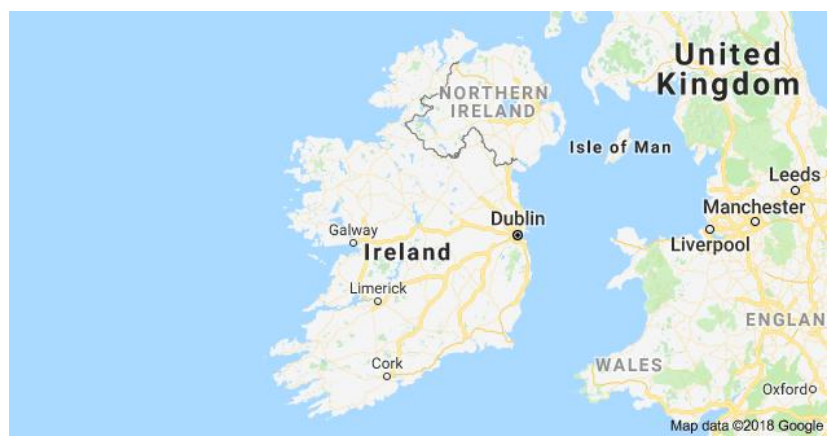

Figure 1. Map of Ireland

Healthcare in Ireland is a two-tiered system of public and private services. Government-funded public hospitals are owned and run by the Health Service Executive (HSE) or are voluntary public hospitals which may be privately operated but funded by the government. The public system, although providing similar quality care to private hospitals, is often overbooked and waiting lists can be long, even for operations that demand some urgency. In fact Ireland, together with the UK and Sweden, had the worst patient feedback on accessibility/waiting time problems among the 35 countries ranked by the Euro Health Consumer Index, with Ireland coming in 21 st. $^{[6]}$
During the global recession of 2007-08, it was suggested that Ireland's resources were not well deployed and cost savings were, in fact, "false economies". The claimed financial savings, in the view of Williams and Thomas, was offset substantially by overtime payments and the need to rely on more expensive agency (temporary) workers. ${ }^{[7]}$ While a key focus across the UK healthcare system during this time of austerity involved a move away from a reliance on doctors in primary care, this was not a policy focus for Ireland. ${ }^{\text {[7] }}$ It was observed that staff nursing numbers fell during the period monitored (2008-2014) but there was an increase in nurse specialists and therapists. In summary, more efficient use could have been made of the resources, in particular those deployed on agency staff and retirement packages. The opportunity to consider a PA role to address the shortfalls in staffing was seen as timely. The UK National Health Service began a national program of activity to support development of the PA workforce in 2016 to address workforce challenges across primary and secondary healthcare settings. ${ }^{[1]}$ Other countries with PA development include Australia, Bulgaria, Canada, India, The Netherlands, and South Africa to name a few; thus, models of PA utilization were available. ${ }^{[8]}$

The public-private mix has been the centre of debate in Ireland over the years as well. Mounting pressure on the Irish government's health budget, with more costs directed to patients themselves has caused premiums to rise. ${ }^{[9]}$ Privatisation in the Irish health sector since the 1980s has come under scrutiny in more recent times with suggestions that the Irish government has supported for-profit healthcare. ${ }^{[10,11]}$ Despite a commitment in 2001 to increase the number of hospital beds, a majority of which were for the public sector, a $34 \%$ increase in these beds was seen in the private sector, as distinctly different from $3 \%$ in the public sector. The focus on healthcare tends to change depending on which political party is in power. In 2016 the opportunity to form a joint healthcare committee across the political spectrum was provided. This committee developed consensus on a long-term policy direction for Ireland's healthcare system to ensure universal access to an affordable, universal, single-tier healthcare system in which patients are treated promptly on the basis of need rather than the ability to pay. ${ }^{[12]}$ From this consensus the adoption of the Irish PA was born.

\section{METHODS}

A mixed-methods preference survey, supported by qualitative free text comments, was administered to Irish citizens across public and private sectors. The aim was to explore patients' willingness to be seen by a PA. Recruited participants were not told what a PA was capable of doing and how the role was organized, but instead was presented as a construct. The 
study used convenience sampling of adults who had not received services from a PA or a nurse practitioner (NP). Those familiar with NPs were excluded because these roles can overlap to some extent in tasks, whereby a role-dependent bias could be introduced. During the four weeks of the study (June 2017), 300 participants who were booked to attend outpatient clinics in a large public teaching hospital were invited to participate in the study and 177 agreed. Permission was obtained from individual consultants (physicians) to access patients in their clinics.

In the private hospital a sample of 100 inpatients were invited to take part in the study and 93 agreed. Both hospitals are located in Dublin North East. Approval was secured for the study via the Ethical Committees of Beaumont Hospital and the Bon Secours Health System. In the public hospital, each participant on a sequential list issued by the consultant's office was sent an invitation to take part in a patient-centered study on their next hospital visit. A Participant Information Leaflet was sent which articulated the reason for the study (without mentioning PAs), benefits of the research, and confirmation that no patient risks were involved. This is standard procedure for any study approved by the Beaumont Hospital Ethics Committees and deemed important prior to obtaining consent to participate in the data collection. For the private hospital, data was collected from patients on the ward, as the private sector does not have a similar volume of patients attending outpatient clinics. To fulfill the Ethics Committee requirement, prior to informed consent, inpatient participants were given the same Patient Information Leaflet content by the research assistant, in advance of requesting consent to take part in the study. The scenarios developed through consensus among an international group of doctors and health services researchers would likely be of some anxiety to a patient but the management of their needs well within the capability of a PA. ${ }^{[3]}$

\subsection{Data collection}

A research assistant approached the surrogate patient in the outpatient clinic of the public hospital and on the wards of the private hospital. Where the participant received information via the post (public hospital) inviting them to participate in a research study (the PA topic was not disclosed), they were asked if they had any questions about the study before requesting consent. Where information was given on the day (in the private hospital), time was given to the participant to ask questions before consent was signed to take part in the study.

Data were collected by structured interview; "patients" were asked to read a brief description of a PA and a doctor:

Published by Sciedu Press
A Doctor is a person skilled in the science of medicine and is trained and licensed to treat sick and injured people.

A PA is a healthcare professional trained in medicine who works as part of a medical team in partnership with doctors to provide medical care to patients.

Following this, one of three randomly selected scenarios was drawn. Each was written on a sheet of paper with the questions giving the choice to be treated by a PA or a doctor. For the purpose of the study, participants acted as surrogate patients for only one of the scenarios, which were as follows:

(1) You stepped out of a car into a hole in the footpath and severely injured your ankle. The ankle is swollen and you are unable to put your weight on your injured foot. When you visit the Emergency Department the receptionist says you can be seen by the doctor in four hours or the PA in one hour. Which one would you choose?

(2) You have a $4 \mathrm{~cm}$ cut in your forearm and blood was spurting before you could get a tourniquet on your arm. When you visit the Emergency Department the receptionist says the doctor can see you in four hours or the PA in one hour. Which one would you choose?

(3) Your 4-year-old daughter falls off the swing, hits her head on a rock and has a $2 \mathrm{~cm}$ gash on her forehead. When you visit the Emergency Department the receptionist says the doctor can see you in four hours or the PA in one hour. Which one would you choose?

For each scenario, after answering the initial question the participant was asked 2 more questions: Would you choose the PA if s/he could see you in 30 minutes or wait 4 hours for the doctor: yes/no? Would you choose the PA if s/he could see you in 2 hours or wait 4 hours for the doctor: yes/no?

\subsection{Data analysis}

Descriptive statistics were used to summarise participants' demographic characteristics for each of the three scenarios tested alongside the choices. The primary outcome was the proportion of individuals in each scenario willing to be treated by a PA for at least one of the time trade-off options offered (presumably with the greatest waiting time reduction). A secondary outcome was the proportion of individuals who changed their answers when the waiting time to see the PA varied, evaluated as the proportion of individuals willing to see PAs across the 3 scenarios.

\section{RESULTS}

There was a $45 \%$ response rate from those invited to take part. A total of 270 respondents took part in the study across two hospitals (one private and one public). The mean age 
was 60 years (range 22-90) with a mix of male $(52 \%)$ and female respondents (48\%). Respondents were classified by Hospital Outpatient Department (OPD) or inpatient Setting, Age, Gender, Parents (whether they had children or not) and Scenario Focus (scenarios $1 \& 2=$ adult-focused or scenario $3=$ child-focused). Table 1 shows total numbers in each wait time category and percent of each category choosing to see the PA in each of the time periods. Binary logistic regression was used to model influence of independent demographic variables on dependent variable (choice of PA or doctor).
Hospital inpatient and OPD settings were related (i.e., each OPD Setting was exclusive to a single hospital); therefore, Hospital was excluded. The MAU (Medical Assessment Unit) contained a low number of responses, none of which chose the doctor in any of the scenarios, so this category was excluded $(n=20)$. Respondents who failed to answer all of the required questions were excluded $(n=1)$. Final sample size for regression $=249$. Dependent variable coded as 0 : Choice $=$ Doctor and 1: Choice $=$ PA. Age was a numeric predictor; all others were categorical.

Table 1. Demographics

\begin{tabular}{|c|c|c|c|c|}
\hline Value & Total & PA 30 mins & PA 60 mins & PA 120 mins \\
\hline Outpatient setting & & $\%$ & $\%$ & $\%$ \\
\hline Cardiology & 82 & 97.6 & 96.3 & 93.9 \\
\hline Endoscopy & 7 & 85.7 & 71.4 & 85.7 \\
\hline Nephrology & 88 & 92.1 & 87.5 & 83.0 \\
\hline \multicolumn{5}{|l|}{ Hospital setting } \\
\hline Medical Assessment Unit & 20 & 100 & 100 & 100 \\
\hline Ward & 73 & 95.9 & 97.3 & 93.2 \\
\hline \multicolumn{5}{|l|}{ Age (years) } \\
\hline$<21$ & 7 & 100 & 87.7 & 100 \\
\hline $21-30$ & 13 & 100 & 92.3 & 76.9 \\
\hline $31-40$ & 21 & 95.2 & 95.2 & 95.2 \\
\hline $41-50$ & 30 & 96.7 & 93.3 & 96.7 \\
\hline $51-60$ & 46 & 95.6 & 95.6 & 95.6 \\
\hline $61-70$ & 48 & 95.8 & 91.7 & 85.4 \\
\hline $71-80$ & 76 & 93.4 & 92.11 & 88.2 \\
\hline $80+$ & 29 & 93.1 & 96.5 & 89.66 \\
\hline \multicolumn{5}{|l|}{ Gender } \\
\hline Female & 128 & 94.5 & 90.6 & 90.6 \\
\hline Male & 142 & 95.8 & 95.8 & 90.1 \\
\hline \multicolumn{5}{|l|}{ Children } \\
\hline No & 63 & 92.06 & 92.1 & 87.3 \\
\hline No Answer & 1 & 100 & 0 & 100 \\
\hline Yes & 206 & 96.12 & 94.2 & 91.3 \\
\hline \multicolumn{5}{|c|}{ Scenario Focus (Children involved) } \\
\hline No & 175 & 95.43 & 92.6 & 90.3 \\
\hline Yes & 95 & 94.74 & 94.7 & 90.5 \\
\hline
\end{tabular}

The majority of respondents chose to see a PA over a doctor based on the scenarios presented, when offered the choice of seeing the PA in 30 minutes versus four hours for the doctor. The data were imbalanced with high numbers of respondents choosing to see the PA in each of the wait time scenarios. Because of the imbalance, the latter models (PA 30 mins and Doctor $120 \mathrm{mins}$ ) struggle to demonstrate that they explain the distribution of the dependent variable better than the null models (see Table 2).

Table 2. Model fit

\begin{tabular}{llll}
\hline Model & Chi Square & df & $\boldsymbol{p}$ \\
\hline PA (1 h) / Doctor (4 h) & 21.298 & 7 & .003 \\
PA (0.5 h) / Doctor (4 h) & 13.527 & 7 & .060 \\
PA (2 h) / Doctor (4 h) & 13.977 & 7 & .052 \\
\hline
\end{tabular}


Despite the potential weakness of the models, they contain would choose to see a PA or wait to see a doctor (see Tables useful information in relation to the importance of the vari- 3-5).

ous predictors in determining whether or not the respondent

Table 3. Coefficients for PA 60-minute wait

\begin{tabular}{|c|c|c|c|c|}
\hline Predictors & Estimate & Std. error & Statistic & $p$ value \\
\hline (intercept) & 5.538 & 1.454 & 3.808 & .000 \\
\hline OPD - Endoscopy & -3.379 & 1.204 & -2.809 & .005 \\
\hline OPD - Nephrology & -2.252 & 0.841 & -2.807 & .007 \\
\hline Ward (inpatient) & 0.386 & 1.091 & 0.354 & .724 \\
\hline Age & -0.036 & 0.020 & -1.753 & .080 \\
\hline Gender - Female & -1.142 & 0.565 & -2.020 & .043 \\
\hline Children - Yes & 1.382 & 0.751 & 1.839 & .066 \\
\hline Scenario Focus - Child & 0.464 & 0.585 & 0.793 & .428 \\
\hline
\end{tabular}

Table 4. Coefficients for PA 30-minute wait

\begin{tabular}{lllll}
\hline Predictors & Estimate & Std. error & Statistic & $\boldsymbol{p}$ value \\
\hline (intercept) & 6.378 & 1.674 & 3.811 & .000 \\
OPD - Endoscopy & -2.680 & 1.401 & -1.913 & .056 \\
OPD - Nephrology & -1.835 & 0.895 & -2.050 & .040 \\
Ward & 0.118 & 1.021 & 0.115 & .908 \\
Age & -0.057 & 0.023 & -2.486 & .013 \\
Gender - Female & -0.408 & 0.619 & -0.659 & .510 \\
Children - Yes & 1.954 & 0.788 & 2.481 & .013 \\
Scenario Focus - Child & -0.194 & 0.620 & -0.313 & .754 \\
\hline
\end{tabular}

Table 5. Coefficients for PA 120-minute wait

\begin{tabular}{lllll}
\hline Predictors & Estimate & Std. error & Statistic & $\boldsymbol{p}$ value \\
\hline (intercept) & 4.276 & 1.064 & 4.019 & .000 \\
OPD - Endoscopy & -1.399 & 1.213 & -1.153 & .249 \\
OPD - Nephrology & -1.448 & 0.575 & -2.517 & .012 \\
Ward & 0.172 & 0.690 & 0.249 & .804 \\
Age & -0.037 & 0.020 & -1.753 & .080 \\
Gender - Female & -0.128 & 0.441 & -0.291 & .771 \\
Children - Yes & 1.179 & 0.555 & 2.126 & .033 \\
Scenario Focus - Child & 0.077 & 0.451 & 0.172 & .864 \\
\hline
\end{tabular}

In terms of odds ratios (see Figure 2), there is evidence that older respondents are less likely to choose the PA but respondents with children are more likely to choose the PA. Some of the largest effect sizes seem to be related to the respondents' reasons for being in the hospital (i.e., their OPD setting). In comparison, outpatient respondents were less likely to choose the PA.

Free text comments from public and private settings were thematically analyzed by checking what comments respon-

Published by Sciedu Press

dents made based on why they choose a PA or a doctor. Those 5\%-8\% choosing a doctor (depending on timelines offered) seemed to focus on the doctor's qualifications, medical knowledge, and trust in this medical provider.

\section{Examples of free text}

Participants gave reasons such as wariness when they were unsure of the expertise of a new health professional. Some free text comments of why some participants chose a doctor over a PA include: 
"Wary of the PA not knowing enough."

"Not sure if qualified enough for the task."
"Prefer doctor because PA is under supervision of doctor."

"More trust in doctor."

\section{Comparative Odds-Ratios of Predictor Categories}

Incl. Significance and 95\% Confidence Intervals
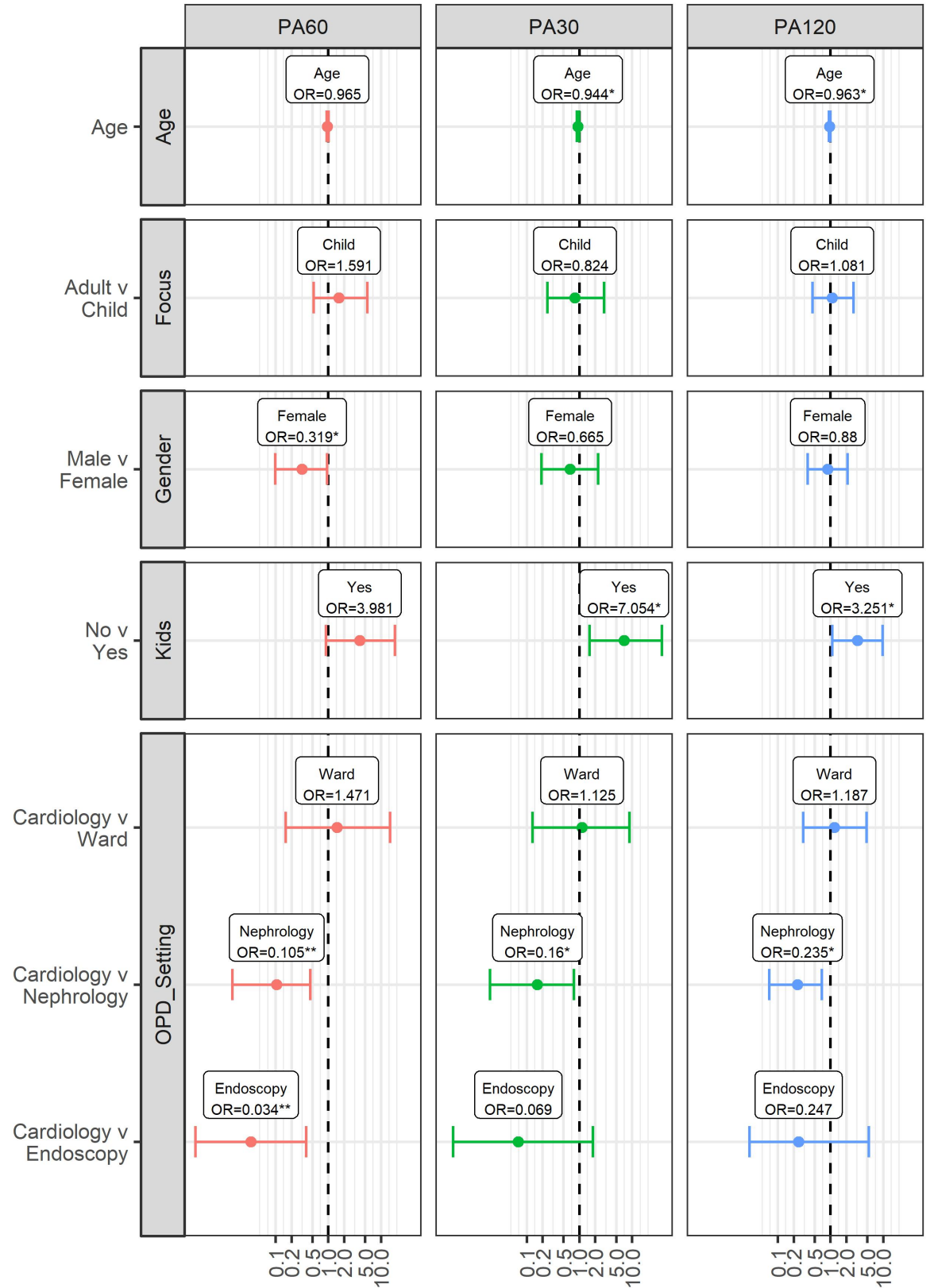

Odds Ratio

Figure 2. Comparative odds-ratios of predictor categories

The following comments are examples from participants who choose a PA over a doctor:

"No point waiting for a diagnosis in 4 hours when you can be assessed in a more timely manner, also cuts back on the number of people waiting."
"The pain would be horrible, and the doctor can be spared for more serious patients. Trust that PA would be qualified enough to deal with this scenario."

"Seen as early as possible by the PA, if any serious injury can be consulted by the doctor immediately." 
"If I see a doctor after an hour, I might not be alive anymore."

"PA can handle non serious issues. It will improve the service for the patients in need."

"I'm 90-year-old I don't have that much time to spare."

"Time is important to me, plus I'd get the same treatment from a doctor."

The free text qualitative data was analyzed and three main themes emerged: wait time, trust, competency, and the seriousness of the condition (see Figure 3).

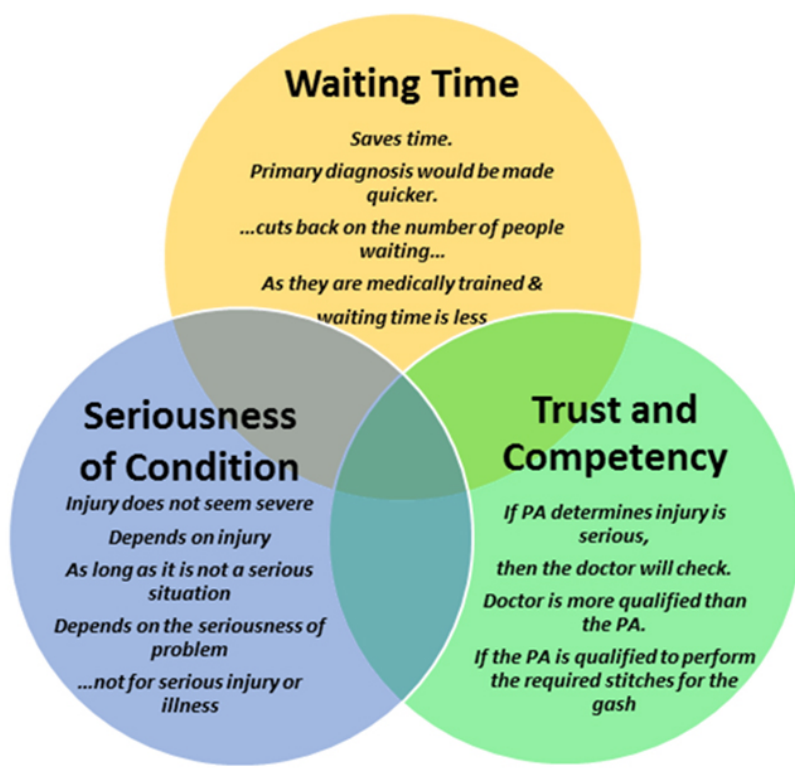

Figure 3. Reasons for willingness to be seen by a PA

The decisions made in this sample appear to be influenced by knowing that the PA is supervized and can check decisions with their supervizing consultant, especially when the medical complaint is serious.

The primary outcome of the study was the proportion of individuals who were willing to be treated by a PA for at least one of the time trade-off options offered (presumably with the greatest waiting time reduction). The findings support this observation. A secondary outcome of the study was the proportion of individuals who changed their answers when the wait time to see the PA varied, evaluated as the proportion of individuals willing to see PAs across the 3 scenarios. The findings identified that five "patients" (PA in 30 minutes) and eight "patients" (PA in 2 hours) would choose the doctor over the PA (4-hour wait).

\section{Discussion}

The decisions made by the participants in this study were influenced by a trade-off of wait time for an urgent medical Published by Sciedu Press condition - shorter time for a PA or longer time for a doctor. For patients attending an emergency department (ED), long waiting times remains a chief complaint for most worldwide. ${ }^{[13,14]}$ The volume of patients requesting care with low to moderate urgency level has led to an increased volume of patients attending the ED and, therefore, an increase in patient wait time. ${ }^{[15]}$ Long wait times can impact patient safety and result in patients leaving the ED before being seen by a doctor. In the 2017 Irish Sláintecare Report, the ED wait time is now set to four hours, from triage to discharge or hospital admission. ${ }^{[12]}$ Increasing clinical activity, such as patient throughput and increased productivity, has been reported as a benefit of the PA role. ${ }^{[16,17]}$ Ireland is among three European countries which share the worst patient accessibility to healthcare. According to the European Health Consumer Powerhouse report, these long wait times are not as a result of scarce resources but rather poor healthcare administrations. ${ }^{[6]}$ In fact, the report emphasized that long wait times are costing these states more money due to inefficiencies in processing patients.

Numerous studies have found that patient preferences for healthcare providers can be highly influenced by patients' previous experiences and the level of trust and confidence they have in the role. ${ }^{[18-20]}$ Comments from participants in this Irish study concur. Trust and competence were influencing factors in the participants' decision whether or not to be seen by a PA. Although the PA role was not yet in place in the study location, and was viewed more as a theoretical medical clinician in these settings, the participants were generally trusting of the role once they understood that the PA was a dependent professional and could check diagnoses and treatments with a doctor. Trust and confidence were found to be engendered by trust and confidence in the wider health system of the UK National Health Service and in General Practice itself. ${ }^{[21]}$ However, organizational trust becomes a critical factor only when interpersonal trust is already present. ${ }^{[22]}$

Although the PA role was established in the UK setting, by the time it was studied by Halter et al., ${ }^{[21]}$ they found, as did Leach et al., ${ }^{[20]}$ and Zheng et al., ${ }^{[23]}$ that patient trust was proportionately related to their judgment of the PA being competent in the clinical activities of assessing, making referrals, initiating treatments, and advising on self-management of their conditions. In addition, these judgments of competence were linked to the patient's previous experience of the PA and their confidence in the PA as a clinician. It seems that where the participants had trust in the PA role, the delegation of care was acceptable to them. ${ }^{[24]}$ However, not all patients in our study had trust and believed in the competence of the PA. This may be due to a lack of familiarity with the role 
of the PA. For participants who were attending the service as private patients, their expectations of being seen by a consultant rather than another clinician may have influenced their decision. According to Leach et al., those preferring doctors over, for example, nurse practitioners or PAs, were more likely to cite qualifications and trust for this group of clinicians, ${ }^{[20]}$ an observation which concurs with Dyer as well. ${ }^{[25]}$

Some studies found that credibility and availability are underlying enablers of trust, especially in the early chain of healthcare. Norberg and colleagues described this chain of trust and healthcare delivery spanning from the moment that a patient calls an ambulance to the various healthcare transitions in the patient's journey. ${ }^{[26,27]}$ Trust matters in healthcare. Calnan \& Rowe suggest that when competence and experience characterize healthcare, the patient believes health professionals will provide adequate treatment and make them feel secure. ${ }^{[28]}$ As trust is viewed as forward looking and can reflect an attitude to a new relationship, this finding is important in preparing the landscape in Ireland for the PA role. Giddens suggests that trust is related to risk and that trust is needed because choices are made with partial knowledge. ${ }^{[29]}$ Such a suggestion is applicable to this study as participants had very limited knowledge of the PA role. While the aim of our study was to explore surrogate patients' willingness to be seen by a PA, before becoming aware of the PA role, patients' trust in clinicians should not be underestimated. Despite the PA role being well-established in the US, Volpe et al. found the need to improve knowledge and perception of American college students regarding the role. ${ }^{[30]}$ Their findings suggest that older students, female students, students with plans to pursue a healthcare career, and those satisfied with care received from a PA had significantly higher levels of knowledge of the role.

While the average age of the participants in our study was 60 years (range 22-90), the recent Irish Census indicates that $18.4 \%$ of the population in Ireland are over the age of 60 , with expected growth to reach 1.15 million people by 2026 or $20 \%{ }^{[31]}$ This means that more patients will be presenting at an older age along with more chronic disease management requirements. Strunk concluded that PA acceptance diminishes once the complexity of the medical procedure increases. ${ }^{[22]}$ Although the Strunk study was published four decades ago, a more recent study concurs with this finding, suggesting that the level of acceptance of the medical professional is an inverse relationship between willingness to use PAs or NPs and acuity of the medical condition. ${ }^{[23]}$ While one-fifth of the patients in the Zheng study did not understand the differences in provider type or their training (PAs, NPs and medical residents), they wanted to know this infor- mation when asked. ${ }^{[23]}$ Strategies to expand the scope of medical providers who are not doctors, should first consider the willingness of patients to be treated by them. ${ }^{[5]}$

On the other hand, incorporating a PA in an acute setting may have advantages which are not fully appreciated by patients. In a New Zealand pilot project, the presence of a PA was seen to result in safer patient care. ${ }^{[32]}$ Doctors and nurses attributed the inclusion of PAs to the presence of a constantly available and knowledgeable healthcare professional who had the capacity to focus on quality and safety, freeing up other staff to do the same. PAs could consistently review unwell patients, passing on their high-level medical understanding to the consultant. The New Zealand evaluation found that teams which included PAs made $24.5 \%$ fewer "patient-at-risk" calls than teams without a PA. ${ }^{[33]}$

In exploring the impact of alternative staffing with PAs and NPs, a retrospective review of 590 admissions to two medical ICUs at one hospital was investigated. ${ }^{[34]}$ Outcomes showed hospital mortality was similar (32\% in both cases): Medical ICU Length of Stay (4.22 days for Medical ICU-NP/PA vs. 4.44 days for Medical ICU-Resident (doctor), and hospital Length of Stay (14.01 for Medical ICU -NP/PA vs. 13.74 days for Medical ICU-Resident). Discharge to a skilled care facility (vs. home) was similar: (37.1\% for Medical ICU -NP/PA vs. 32.5 per cent for Medical ICU -Resident). After multivariate adjustment, Medical ICU staffing type was not associated with hospital mortality, Medical ICU Length of Stay, hospital Length of Stay, or post-hospital discharge destination.

\section{Strengths and limitations}

This is the first study to explore the willingness of a citizen to be seen by a PA from the Irish perspective. The apparent willingness of respondents in this study to utilize PAs (at least in theory) leads to an imbalanced dataset which, coupled with the small sample size and convenience sampling, limits the statistical inferences. While this is a snapshot of Irish people's preferences for a medical provider across the public and private sectors, a larger sample size is not likely to reveal much more unless the scenarios were changed and the time trade-off less significant. Although the characteristics of the sample were not similar across the settings, the age mix and gender suggest representation is more similar than different from a cross section of Irish people. This study sets the stage for more investigation as to what is preferred in healthcare personnel as the wait time for care lengthens.

\section{Conclusions}

In a cross section of Irish patients, it appears most are willing to be seen by a PA when time is a variable. Simply put, if 
they can see a PA quicker than any other clinician, then expediency is a primary motivator. Based on a growing body of literature across a wide spectrum of countries, willingness to be seen by a PA does not appear to have been influenced, up to now, by gender, age, occupation, language, or parenthood. However, our study suggests that age and parenthood may have an effect on Irish patients' willingness to be seen by a PA. Similar to previous studies, comments from participants of this study suggest that a medical professional is judged by the overall experience of the care given such as wait time, and whether the PA is considered to be competent. When new ways of working are introduced into a health system, there is a need to communicate these plans to patients and test their responses to such plans. Building patient confidence is key to the success of designing and developing the

\section{REFERENCES}

[1] Aiello M, Roberts KA. Development of the United Kingdom physician associate profession. Journal of the American Academy of Physician Assistants. 2017; 30(4): 1-8. PMid:28350738. https: //doi.org/10.1097/01. JAA.0000513357.68395.12

[2] Kuilman L, Nieweg RMB, van der Schans CP, et al. Are Dutch patients willing to be seen by a physician assistant instead of a medical doctor? Human Resources for Health. 2012; 10(9): 34-40. https : //doi .org/10.1186/1478-4491-10-28

[3] Hooker RS, Harrison K, Pashen D. Are Australians willing to be treated by a physician assistant? Australasian Medical Journal. 2010; 3(7): 407-413. https : //doi .org/10.4066/AMJ . 2010. 325

[4] Doan Q, Hooker RS, Wong H, et al. Will Canadians accept care by physician assistants? Canadian Family Physician. 2012; 58(7): e459-464. PMid:22893348.

[5] Larkin GL, Hooker RS. Patient willingness to be seen by physician assistants, nurse practitioners, and residents in the emergency setting: does the presumption of assent have an empirical basis? American Journal of Bioethics. 2010; 10(8): 1-10. PMid:20694894. https://doi.org/10.1080/15265161.2010.494216

[6] Health Consumer Powerhouse (HCP). Euro Health Consumer Index 2015. Health Consumer Powerhouse, Marseillan, France. 2016.

[7] Williams D, Thomas S. The impact of austerity on the health workforce and the achievement of human resources for health policies in Ireland (2008-2014). Human Resources for Health. 2017; 15(62): 1-8. https://doi.org/10.1186/s12960-017-0230-3

[8] Ballweg RM, Hooker RS. Observations on the global spread of physician assistant education. Journal of Physician Assistant Education. 2017; 28: S75-S80. PMid:28961628. https://doi .org/10.109 7/JPA. 0000000000000154

[9] Turner B. Putting Ireland's health spending into perspective. 2018; 391: 833-834. Available from: www. thelancet.com

[10] Burke SA, Brugha R, Thomas S. It's the economy, stupid! When economics and politics override health policy goals -the case of tax reliefs to build private hospitals in Ireland in the early 2000s [version 1; referees: awaiting peer review] HRB Open Research. 2018; 1 : 1-10. https://doi.org/10.12688/hrbopenres. 12784.1 health sector service. While further research is needed to evaluate the patient experience of consulting with a PA, it is paramount to have baseline data for countries considering introducing this role.

\section{ACKNOWLEDGEMENTS}

We acknowledge the Royal College of Surgeons in Ireland (RCSI) Research Summer School for funding this study and providing research assistants Theivanai Saroja Ramaiah, Sze Wei Lim and Asaad Alwabry. We also acknowledge the assistance of Eric Clarke for initial data analysis of the study. Reviewers, both anonymous and known, contributed to this analysis and we are grateful for their input.

\section{CONFLICTS OF INTEREST Disclosure}

The authors declare no conflicts of interest.

[11] Mercille J. Privatization in the Irish hospital sector since 1980. Journal of Public Health. Feb 2018. PMid:29462359. https ://doi.or $\mathrm{g} / 10.1093 / \mathrm{pubmed} / \mathrm{fdy} 027$

[12] Houses of the Oireachtas Committee on the Future of Healthcare (2017). Sláintecare Report, Houses of the Oireachtas, Dublin.

[13] Theunissen BH, Lardenoye S, Hannemann PH, et al. Fast Track by physician assistants shortens waiting and turnaround times of trauma patients in an emergency department. European Journal of Trauma in Emergency Surgery. 2014; 40: 87-91. PMid:26815782. https://doi .org/10.1007/s00068-013-0324-0

[14] Johnson KD, Winkelman C. The effect of emergency department crowding on patient outcomes: a literature review. Advanced Emergency Nursing Journal. 2011; 33(1): 39-54. PMid:21317697. https : //doi.org/10.1097/TME.0b013e318207e86a

[15] Doetzel CM, Rankin JA, Then KL. Nurse practitioners in the emergency department: Barriers and facilitators for role implementation. Advanced Emergency Nursing Journal. 2016; 38: 43-55. PMid:26817430. https://doi.org/10.1097/TME. 000000000 000090

[16] Ducharme J, Alder RJ, Pelletier C, et al. The impact on patient flow after the integration of nurse practitioners and physician assistants in 6 Ontario emergency departments. Canadian Journal of Emergency Medicine. 2009; 11(5): 455-61. https://doi.org/10.1017/S1 481803500011659

[17] Dies N, Rashid S, Shandling M, et al. Physician assistants reduce resident workload and improve care in an academic surgical setting. Journal of the American Academy of Physician Assistants. 2016; 29(2): 41-46. PMid:26818645. https://doi.org/10.1097/01 .JAA. 0000476214.34937 .50

[18] Roblin DW, Becker ER, Adams K, et al. Patient Satisfaction with Primary Care: Does Type of Practitioner Matter? Medical Care. 2004; 42(6): 597-590. https://doi.org/10.1097/01.mlr.000 0128005.27364 .72

[19] Tataw DB, Bazargan-Hejazi S, James FW. Health services utilization, satisfaction, and attachment to a regular source of care among participants in an urban health provider alliance. Journal of Health and Human Services Administration. 2011; 34: 109-41. PMid:21847878. 
[20] Leach B, Gradison M, Morgan P, et al. Patient preference in primary care provider type. Healthcare. 2017.

[21] Halter M, Wheeler C, Drennan VM, et al. Physician associates in England's hospitals: a survey of medical directors exploring current usage and factors affecting recruitment. Clinical Medicine. 2017; 17(2): 126-31. PMid:28365621. https://doi.org/10.7861/cl inmedicine.17-2-126

[22] Strunk HK. Patient attitudes towards physician's assistants. California Medicine. 1979; 118(6): 73-77.

[23] Zheng S, Fu Hui S, Yang Z. Hospital trust or doctor trust? A fuzzy analysis of trust in the health care setting. Journal of Business Research. 2017; 78: 217-225. https://doi.org/10.1016/j.jbus res. 2016.12 .017

[24] Drennan VM, Gabe J, Halter M, et al. Physician associates in primary health care in England: A challenge to professional boundaries? Social Science \& Medicine. 2017; 181(9): e16. https: //doi.org/10.1016/j.socscimed.2017.03.045

[25] Dyer TA, Owens J, Robinson PG. The acceptability of care delegation in skill-mix: the salience of trust. Health Policy. 2014; 117: 170-178. PMid:24685199. https://doi.org/10.1016/j.healthpol. 20 14.02 .013

[26] Norberg BG, Christensson L, Wireklint SB, et al. Use of the emergency medical services by patients with suspected acute primary healthcare problems: Developing a questionnaire to measure patient trust in healthcare. European Journal for Person Centered Healthcare 2016; 4(3): 444-452. https://doi.org/10.5750/ejpch.v4i3 .1120

[27] Norberg BG, Nyströmb M, Christenssonc L, et al. Trust in the early chain of healthcare: lifeworld hermeneutics from the patient's per- spective. International Journal of Qualitative Studies on Health and Well-Being. 2017; 12: 13566740. https://doi.org/10.1080/17 482631.2017 .1356674

[28] Calnan M, Rowe R. Trust matters in Health Care. State of Health. Maidenhead: Open University Press. 2008.

[29] Giddens A. Risk, trust, reflexivity. In: Beck U, Giddens A, Lash S, editors. Reflexive modernisation: politics, tradition, and aesthetics is the modern social order. Cambridge: Polity Press; 1994. 211-22 p.

[30] Volpe M, Bulmer S, Kelsey C. Knowledge and perceptions of college students regarding the physician assistant profession. Cureus. 2015; 7(10): e368. https://doi.org/10.7759/cureus . 368

[31] Census. Summary results Ireland's Census. 2016. Available from: http://www.cso.ie/en/csolatestnews/presspages/2017/ census2016summaryresults-part1/ Accessed 16/12/17.

[32] Martin D, Abelson J, Singer P. Participation in health care prioritysetting through the eyes of the participants. Journal of Health Services Research and Policy. 2002; 7(4): 222-229. PMid:12425781. https://doi.org/10.1258/135581902320432750

[33] Siggins M. Evaluation of the Physician Assistant Trial. Final report prepared for Health Workforce New Zealand by Siggins Miller. 2012. Available from: http://www.parliament.nz/resource/minz/ 50SCHE_EVI_0ODBSCH_FIN_11729_1_A326491/b7edbd08f 1d 8d307266cd125390c4ce4aa0f4028 Accessed 22/3/16.

[34] Gershengorn HB, Wunsch H, Wahab R, et al. Impact of NonPhysician Staffing on Outcomes in a Medical ICU. CHEST. 2011; 139(6): 1347-53. PMid:21393397. https://doi.org/10.1378/ chest. 10-2648 